\title{
Modulation of Dextran Sulphate Sodium-Induced Colonic Inflammation by Local Supplementation of Leptin
}

\author{
Corinne Nazaret ${ }^{1}$, Sandra Guilmeau ${ }^{1}$, Yassine Sakar ${ }^{1}$, Francine Walker ${ }^{1}$, Robert Ducroc ${ }^{1}$, \\ Thomas Aparicio ${ }^{1}$, Thérèse Lehy ${ }^{1}$, Christine Linard ${ }^{2}$ and André Bado ${ }^{*}, 1$ \\ ${ }^{I}$ INSERM, U773, Centre de Recherche Biomédicale Bichat Beaujon; UFR de Médecine Paris 7 - Denis Diderot; IFR02 \\ Claude Bernard, 16 rue Henri Huchard, BP 416, F-75018, Paris, France \\ ${ }^{2}$ Institut de Radioprotection et de Sûreté Nucléaire, Direction de la Radioprotection de l'Homme, Laboratoire de Radio- \\ pathologie 92262 Fontenay-aux roses Cedex, France
}

\begin{abstract}
Background \& Aims: Leptin is overproduced in gastrointestinal mucosa during inflammatory processes, suggesting that mucosal cells represent sources of secreted leptin active in the lumen. The effects of leptin, acting apically from colonic epithelial cells, were analysed on dextran sulphate sodium-induced colonic inflammation in rats.

Methods: We determined the effects of intracolonic leptin on the phosphorylation of STAT3, MAPkinase and on colon mucosa-derived inflammation-related genes (IL-8, IL1 $\beta, \mathrm{TNF} \alpha, \mathrm{COX}-2)$. Colitis was induced by administering dextran sodium sulphate. The effects of intracolonic leptin on DSS colitis was evaluated based on disease symptoms, cytokine expression and PPAR $\alpha, \gamma$.

Results: In vivo, intracolonic leptin rapidly stimulated STAT-3 and p42-MAPK phosphorylation. We also detected a 3fold increase in COX-2 induction, and a dose-dependent increase in mucosal $\mathrm{PGE}_{2}$ content $\left(\mathrm{EC}_{50} 0.89 \mathrm{nM}\right)$. Intracolonic leptin reduced the severity of DSS-induced colitis, whereas intraperitoneal leptin exacerbated colitis. Intracolonic leptin decreased DSS-induced inflammatory IL-8 (-75\%; $P<0.01 v s$ DSS) and IL-1 $\beta$ ( $-60 \% ; P<0.01 v s$ DSS); it also prevented a DSS-induced decrease in the levels of mucosa PPAR $\alpha$ mRNA and increased the levels of PPAR $\gamma$ mRNA two-fold $(P<0.01$ vs DSS $)$.

Conclusion: Leptin activates its apical receptor and this mechanism coupled to the activation of STAT-3 and MAPKinase signalling pathways may have a beneficial effect on the integrity of the epithelium upon mucosa injury. These data shed further light on the role of gastrointestinal luminally acting leptin in the modulation of intestinal inflammation.
\end{abstract}

Keywords: Leptin, local action, dextran sulfate sodium, inflammation, colon, PPARs.

\section{INTRODUCTION}

Leptin, the $o b$ gene product, initially described as a fat tissue-specific protein [1], is produced by other tissues and organs [2-5]. The biological actions of leptin are relayed by leptin receptors $[6,7]$ belonging to the class I cytokine receptor family. This family includes gp-120, the common signal transduction receptor for the IL-6-related family of cytokines. It is now generally accepted that leptin not only regulates food intake, but also participates in various biological processes. In this regard, extensive studies have implicated leptin in the regulation of both innate and adaptive immune responses [8, 9]. In particular, mice deficient for leptin $(o b / o b)$ are resistant to colitis, and the treatment of these mice with circulating leptin confers susceptibility to inflammation [10]. This resistance to intestinal inflammation was also associated with reduced cytokine secretion, increased apoptosis of lamina propria lymphocytes (LPL), and was shown to largely involve $\mathrm{T}$ cell-mediated intestinal

*Address correspondence to this author at the INSERM, U773 - CRB3/E02, UFR de Médecine Paris 7 - Denis Diderot, 16, rue Henri Huchard, 75018 Paris, France; Tel: 33 (1) 448561 31; Fax: 33 (1) 422887 65;

E-mail: andre.bado@inserm.fr autoimmunity $[11,12]$. In contrast to this pro-inflammatory role of systemic leptin, there is evidence for leptin in anantiinflammatory role. Indeed, $o b / o b$ mice were more likely to succumb after the administration of TNF $\alpha$, an effect that is prevented by replacing leptin [13, 14]. Moreover, leptin protects against acute pancreatitis and is up-regulated in parallel during acute pancreatitis [15]. Furthermore, leptin protects against gastric mucosa injury induced by NSAIDs and alcohol $[16,17]$, and decreases the severity of acetic acid-induced colitis in rats [18].

By contrast, over-production of leptin has been demonstrated in gastric mucosa colonised with Helicobacter pylori $[19,20]$ in the pancreas during acute pancreatitis [15], and in the colon of patients with inflammatory bowel disease [21, 22]. Whether leptin up-regulation after tissue injury is causative in inflammatory responses or simply a marker of inflammation has not been formally proven. Thus, identifying the exact relationship between luminal leptin and intestinal inflammation remains to be determined. The aim of this study was to analyse the role of gut leptin acting apically from colonic epithelial cells (CEC) in the modulation of colonic inflammation using a DSS colitis model. We first determined the acute effects of intracolonic leptin on the activation of STAT3, MAPkinase signalling pathways, and 
on colon mucosa-derived IL-8, IL1 $\beta$, TNF $\alpha$ and COX-2 genes in rats. We then evaluated the chronic effects of intracolonic leptin on DSS-induced colonic inflammation and analysed the possible mechanisms involved.

\section{MATERIALS AND METHODS}

Animals. Male Wistar rats weighing 220-250g (Elevage Janvier, France) were caged under standard laboratory conditions with tap water and regular rat chow provided ad libitum, in a $12 \mathrm{~h} / 12 \mathrm{~h}$ light/dark cycle, at a temperature of 21$23^{\circ} \mathrm{C}$. All animals were treated in accordance with the European Committee Standards concerning the care and use of laboratory animals and the experiments were conducted in accordance with the French regulations for animal experiments and with authorization Order $\mathrm{N}^{\circ}$ B75-18-02 received from the Ministry of Agriculture and Prefecture de Paris, France.

Determination of leptin levels in plasma and luminal contents of colon. 24-hour fasted rats were anesthetised, and blood samples were collected from the abdominal aorta. The samples were centrifuged and the plasma was stored at $20^{\circ} \mathrm{C}$ until leptin radioimmunoassays. The rats were then killed and the colon, from after the caecum to rectum, was removed and luminal contents from the colon were collected. The collected contents were cleared by centrifugation (3000 rpm for 10 minutes), and the supernatants were stored at $20^{\circ} \mathrm{C}$ until analysis by leptin RIA (RIA kits Linco Research Inc., St Charles, Missouri). Size exclusion chromatography (SEC) was carried out using a Superdex 200 column (Pharmacia Biotech, Freiburg, Germany), as previously described [23].

Effects of intracolonic leptin on TNF- $\alpha$, IL-8, IL-1 $\beta$ and COX-2 expression. 24-hour fasted rats were slightly anesthetised with sodium pentobarbital (Sanofi, Libourne, France) and injected with vehicle PBS (control group) or 3 $\mathrm{nM}$ recombinant murine leptin (R\&D systems), slowly administered through a catheter inserted rectally into the colon. The animals were killed 15, 30 and 60 min after injection for the western blot analysis of phosphoproteins. In a second set of experiments, 3 hours after the injection of vehicle or $3 \mathrm{nM}$ leptin, the colon was removed. One part was fixed in Bouin solution, embedded in paraffin, sectioned at $4 \mu \mathrm{m}$, and stained with Alcian blue (AB, $\mathrm{pH} 2.5)$; this was followed by the periodic acid-Schiff reaction (PAS) and counterstaining with haematoxylin. The Blue alcian (AB)/Schiff Periodic acid (PAS) method yielded a blue colour if mostly acidic mucins were present and magenta if mostly neutral mucins were present. Another segment was rinsed with ice-cold $0.9 \%$ saline and the mucosa was scraped and immediately frozen for total RNA and protein extraction. The protein extracts were used for western blot analysis and for determining the $\mathrm{PGE}_{2}$ content by RIA using the $\left[{ }^{125} \mathrm{I}\right]-$ prostaglandin- $E_{2}$ RIA Kit (Perkin Elmer, Zaventem, Belgium).

Western blot analysis. Unfrozen colon mucosa were homogenised at $4^{\circ} \mathrm{C}$ in lysis buffer containing $0.1 \%$ Triton $\mathrm{X}-100,1 \mu \mathrm{g} / \mathrm{ml}$ phenylmethyl sulphonyl fluoride (PMSF), 50 $\mathrm{mM}$ Tris/HCl, $10 \mathrm{mM}$ EDTA, phosphatase inhibitor cocktail, and $0.1 \%$ protease inhibitor cocktail (SIGMA, Saint Louis Mo, USA). Samples were centrifuged at 15,000 g for $30 \mathrm{~min}$ at $4{ }^{\circ} \mathrm{C}$ and the supernatant protein concentrations were quan- tified using the BCA protein assay kit (Pierce, Rockford IL, USA). Proteins were resolved on $8-13 \%$ polyacrylamide gels, transferred onto nitrocellulose membranes and probed overnight with polyclonal rabbit antibody against STAT3, phospho-STAT3 (Tyr705), SOCS-3 from Novus Biologicals, Inc. (Littleton, CO, USA), ERK-1 from Santa Cruz Biotechnology (California, USA), each used at a dilution of 1:1000, and monoclonal mouse antibody phospho p44/p42 MAPK (Thr202/Tyr204) from Cell Signaling Technology, Inc. (Boston, MA). Monoclonal anti- $\beta$ actin (clone AC-74 Sigma, St Louis Mo USA) was used as a loading control at a 1:5000 dilution.

The membranes were incubated with two horseradish peroxidase-conjugated secondary antibodies: donkey antirabbit (Santa Cruz Biotechnology, CA) and goat anti-mouse (Sigma, UK), diluted 1:10,000. The immune complexes were detected by an enhanced chemiluminescence detection system (Pierce, Rockford, IL, USA).

Induction of colitis with DSS. Colitis was induced with $5 \%(\mathrm{w} / \mathrm{v})$ DSS (ICN Biomedicals Inc.) for 7 days; this was followed by 5 days of water intake as described previously [24]. Rats receiving drinking water (control) and DSS were treated once a day with intraperitoneal saline (control) or 6 $\mathrm{nmol} / \mathrm{kg}$ recombinant murine leptin, with intracolonic PBS (control) or $6 \mathrm{nM}$ leptin. The rats were killed on day 12, and the entire colon (from the caecum to anus) was excised and colon length was measured. Each colon was opened and assessed for colitis. A distal colon segment was removed to determine the tissue-associated myeloperoxidase (MPO) activity. Another segment from the proximal and middle colon was removed, rinsed and the mucosa was scraped to isolate total RNA and protein.

Clinical and histological assessment of colitis. The body weight and clinical signs of colitis, such as appearance of diarrhoea and blood in the stools, were determined daily after the start of DSS. We determined the disease activity index (DAI) by applying a score system as previously described [25]. For histological analysis, segments of distal colon were fixed in Bouin solution, were processed by various techniques described above, and were examined by light microscopy. Two pathologists (FW and TL), blinded to the protocol, carried out the histological scoring using the scheme modified by Barbier et al. [26].

MPO activity determination. Tissue myeloperoxidase (MPO) activity was determined using the O-dianisidine hydrochloride method as previously described [27]. Protein concentrations of each sample were determined using the Bio-Rad protein assay (Bio-rad Laboratories, Richmond, CA).

Quantitative real-time polymerase chain reaction (qRT-PCR). Total RNA was extracted from colon mucosa samples with the RNeasy kit (Qiagen). The mRNA levels of inflammation-related cytokines and PPARs, and of the housekeeping gene hypoxanthine-guanine phosphoribosyltransferase (HPRT) were measured by real-time polymerase chain reaction (RT-PCR), as previously described [28] with the primer sequences listed in Table 1 . We used the comparative $\Delta \Delta \mathrm{C}_{\mathrm{T}}$-method for the relative mRNA quantification of target genes, normalised to an endogenous reference (HPRT) and a relevant control equal to $2^{-\Delta \Delta \mathrm{CT}}$. 
Table 1. Sequences of Custom Primers for Real-Time Quantitative PCR

\begin{tabular}{|c|c|c|}
\hline Gene & Forward Primer & Reverse Primer \\
\hline \hline PPAR- $\alpha$ & CCTCTTCCCAAAGCTCCTTCA & GTACGAGCTGCGCATGCTC \\
\hline PPAR- $\gamma$ & TCATGACCAGGGAGTTCCTCA & TCATCTAATTCCAGTGCATTGAACTT \\
\hline TNF- $\alpha$ & CATCTTCTCAAAATTCGAGTGACAA & TGGGAGTAGACAAGGTACAACCC \\
\hline IL-1 $\beta$ & CAACAAAAATGCCTCGTGC & TGCTGATGTACCAGTTGGG \\
\hline CINC $($ IL 8$)$ & GACTGTTGTGGCCCGTGAG & CCGTCAAGCTCTGGATGTTCT \\
\hline COX- 2 & GCAAATCCTTGCTGTTCCAATC & GGAGAAGGCTTCCCAGCTTTTG \\
\hline HPRT & GCTCGAGATGTCATGAAGGAGA & TCAGCGCTTTAATGTAATCCAGC \\
\hline
\end{tabular}

Statistical analysis. The results are expressed as the mean \pm SEM. Results were compared by one-way analysis of variance (ANOVA), followed by a Tukey-Kramer multiple comparisons test if significant results were obtained.

\section{RESULTS}

Leptin detection in colonic luminal contents. Leptinimmunoreactive (IR) protein was detected in the luminal contents from the colon (at levels two-fold lower than circulating leptin levels in non-fasted rats (Fig. 1A).

Intracolonic leptin phosphorylates STAT-3 and ERK proteins, and induces SOCS-3 protein production. We administered leptin directly into the colon lumen and investigated the activation of leptin-receptors coupled to STAT and MAPKinase pathways to test if luminal leptin had any biological effects on the colonic mucosa. Immunoblotting of extracts from colon mucosa treated for $30 \mathrm{~min}$ with intracolonic leptin (3nM) showed that STAT-3 and ERK phosphorylation were significantly increased $(\mathrm{P}<0.01)$. This leptin-induced phosphorylation was even more prominent for p42 MAPK. We observed an even greater degree of STAT3 phosphorylation together with a parallel decrease in $\mathrm{p} 42$ MAPK phosphorylation 60 mins after administration. Moreover, the protein levels of mucosa SOCS-3 protein, a negative regulator leptin-receptor signalling, were greater 60 min after the administration of IC leptin.

IL-1 $\beta$, IL- 8 and TNF- $\alpha$ mRNA levels showed no significant change three hours after the administration of $3 \mathrm{nM} \mathrm{IC}$ leptin, whereas COX-2 mRNA levels were 3-fold greater in colon mucosa (Fig. 2A). Interestingly, COX-2 induction by luminal leptin paralleled a substantial and dose-dependent production of mucosa $\mathrm{PGE}_{2}$, with a 2.8 -fold greater production $(P<0.05 v s$ vehicle) being observed with $3 \mathrm{nM}$ leptin (Fig. 2B). The calculated $\mathrm{EC}_{50}$ from the dose-response curve was $0.89 \mathrm{nM}$. These data indicate that intracolonic leptin induces rapid activation of STAT-3 and ERK proteins; this activation is accompanied by the induction of COX-2 expression and increased production of $\mathrm{PGE}_{2}$ in the colonic mucosa.

Histological analysis of colon mucosa sections from rats treated either with intracolonic PBS- or leptin $(3 \mathrm{nM})$ after 3 hours showed no change in the architecture of the colonic mucosa (Fig. 3). However, despite no obvious changes in the number of goblet cells, 3 hours after intracolonic leptin treatment, an increase in mucus materials was detected in the crypt lumen and in the colon lumen in accordance with our previous demonstration [21].
A

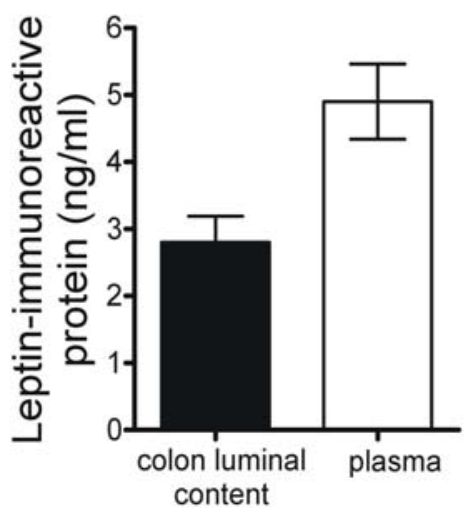

B

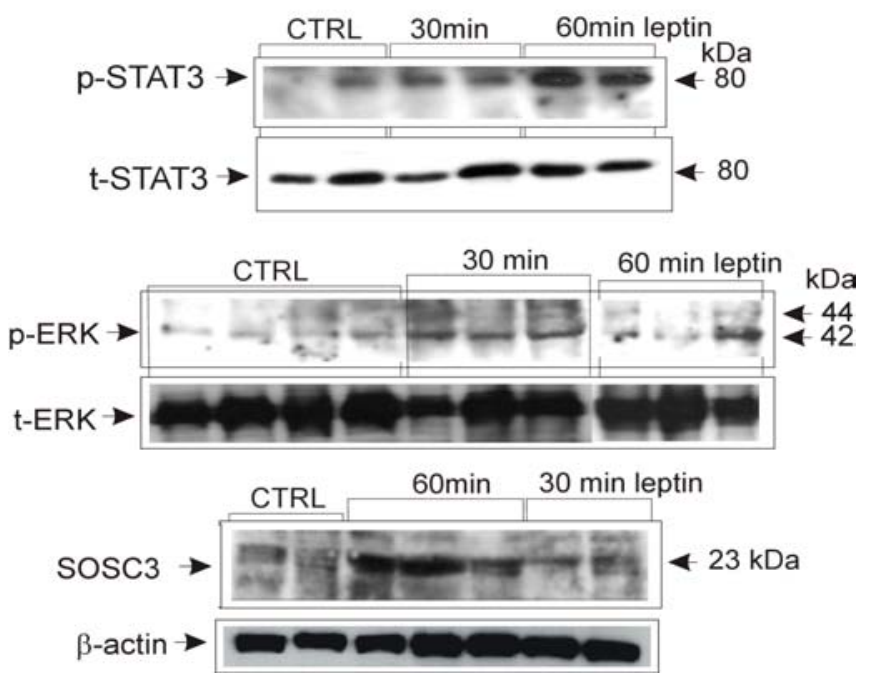

Fig. (1). Leptin in the luminal content of rat colon, and the phosphorylation of STAT3, and ERK proteins. (A) In fluids collected from the colons of rats fed ad libitum and 24 hour-fasted, leptin-immunoreactive (IR) protein was detected, each column representing mean \pm SEM. (B) Vehicle (Control) or leptin was directly delivered into the colon lumen of 24 hour-fasted rats. The rats were killed $30 \mathrm{~min}, 60 \mathrm{~min}$ and 5 hours after injection, the distal colon was removed, and the mucosa was scraped and divided in two fractions, rapidly frozen until use. Proteins extracts were analysed by western blot with antibodies specific for either phosphorylated STAT3, total STAT-3, phosphorylated p42 MAPK, total ERK and SOCS-3 protein; $\beta$-actin was used as a protein loading control. 
A

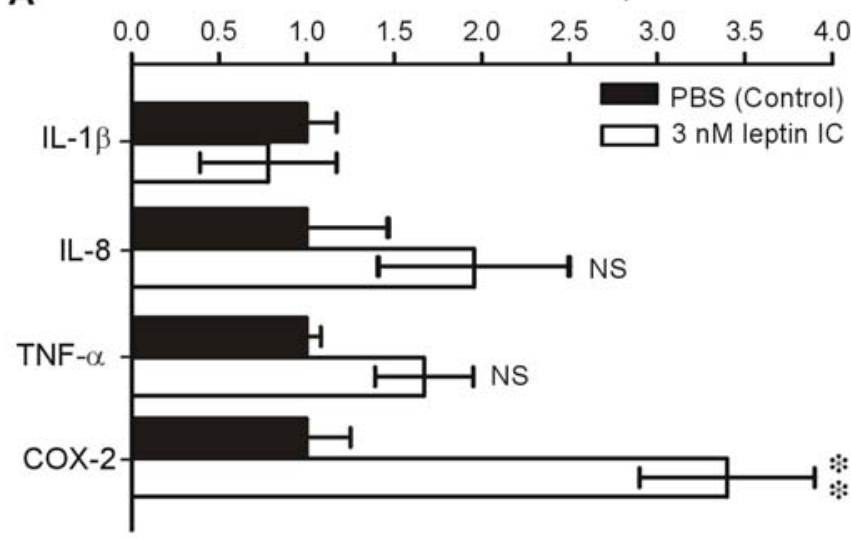

B

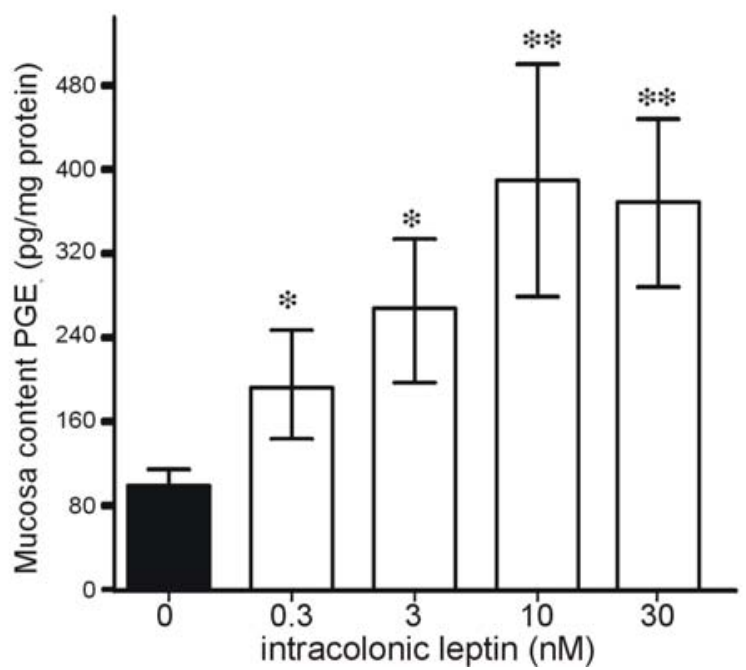

Fig. (2). Acute intracolonic leptin affects inflammation-related genes, induces COX-2 and releases PGE2. (A) mRNA levels of TNF- $\alpha$, IL- 8 , IL $1 b$ and COX-2 were quantified by real-time PCR from total RNA extracted from colonic mucosa isolated from 24hour food-deprived rats treated for 3 hours with intracolonic PBS (control) or $3 \mathrm{nM}$ leptin. Values are normalised to the levels of HRPT mRNA. Each column represents the mean \pm SEM of 8 rats per group. ${ }^{*} P<0.01 v s$ control. (B) Dose-response effect of intracolonic (IC) administration of leptin on colon mucosa $\mathrm{PGE}_{2}$ content. Fasted rats were slightly anesthetised and leptin was directly delivered into the lumen of the colon. Animals were killed 5 hours later, and the distal colon mucosa was scraped and homogenised as described in Material and Methods. The extracts were used for radioimmunoassays of prostaglandin $E_{2}$. Each column represents the mean \pm SEM of $8-10$ rats. ${ }^{*} P<0.01 ; * * P<0.01$ vs control (0).

The chronic effects of intracolonic $v s$ intraperitoneal leptin were further analysed in this rat model of colitis induced by DSS.

Intracolonic leptin attenuates the clinical score of DSS-treated rats. IP or IC leptin had no significant effect on body weight in control rats but did modify the decrease in body weight observed in DSS-treated rats (Fig. 4a). DSStreated rats had significantly lower body weights than control rats. Also, DSS-treated rats administered $6 \mathrm{nmol} / \mathrm{kg}$ IP leptin displayed even lower body weights than rats treated solely with DSS, after the DSS treatment was stopped. By contrast, no further decrease in body weight occurred in DSS-treated rats receiving $6 \mathrm{nM}$ IC leptin. Instead, these rats had slightly higher bodyweights than DSS-treated rats administered 6 $\mathrm{nmol} / \mathrm{kg}$ IP leptin. The decrease in length of colons in DSStreated rats receiving IC leptin was less pronounced than in those receiving vehicle alone; DSS rats receiving IP leptin had similar colon lengths to those receiving IC leptin (Fig. 4b). The clinical score (Fig. 4c) reflecting disease activity was significantly enhanced 6 days after the start of DSStreatment. In DSS-treated rats receiving IP leptin, this score was further enhanced, with aggravation appearing as soon as day 4. This remained highly significant after the stop of DSS up to day 11 in comparison with DSS-treated rats receiving vehicle $(P<0.01$; day to day). The clinical score of DSStreated rats receiving IC leptin was significantly lower than that observed in DSS-treated rats receiving either vehicle or IP leptin (Fig. 4c). The increase in tissue-associated MPO activity, an index of neutrophil accumulation in DSS-treated rats, was also significantly lower $(25 \%, P<0.05 v s$ DSS $)$ in DSS-treated rats receiving IC leptin than in those with vehicle alone, and remained unmodified in DSS-treated rats receiving IP leptin (Fig. 4d).

Histology of colonic sections was performed in DSStreated rats receiving IP leptin or IC leptin (Fig. 5). In normal colonic mucosa, the crypts were straight with their base resting on the muscular mucosa (Fig. 5a). Colons from DSStreated rats showed the infiltration of inflammatory cells, submucosal oedema, and areas of epithelial erosion with early regenerative changes (Fig. 5c). The histological changes in DSS-treated rats receiving IC leptin (Fig. 5d) were not significantly different from those observed in DSS rats treated with vehicle. We observed a more severe disruption of the colonic epithelium in colonic sections of DSS rats receiving IP leptin (not shown): a loss of entire crypts, ulceration and small area of re-epithelisation in comparison with the colonic mucosa of control DSS-treated rats. Overall, the total histological score of DSS rats receiving vehicle was further enhanced in DSS rats receiving IP leptin and was slightly but significantly lower in DSS rats receiving IC leptin (Fig. 5e). These data prompted us to analyse the mucosal expression of cytokines as another indication of the degree of intestinal inflammation after administering IC leptin.

Inflammation-related genes in DSS-rats treated with IC leptin. There were significant changes in the distal colon of DSS-treated rats, i.e. severe disruption of the epithelium with ulceration; thus, we used segments of proximal and transverse colon for real-time PCR analysis. Intracolonic vehicle-DSS-treated rats exhibited a slight but non significant increase in mucosal TNF- $\alpha$ mRNA, a 4-fold increase in mucosal IL- $1 \beta$ mRNA and a significant 35 -fold increase in mucosal IL-8 mRNA levels (Fig. 6). DSS-induced expression of mucosal IL- $1 \beta$ and IL- 8 was strongly decreased by 6 nM IC leptin. Note that large doses of IC leptin did not significantly affect basal mucosa TNF- $\alpha$ and IL- $1 \beta$ mRNA levels but induced a 1.5-fold increase in the levels IL-8 mRNA.

Intracolonic leptin treatment restores PPAR $\alpha$ and enhances PPAR $\gamma$ expression in DSS-treated rats. We extended the analysis of mucosal cytokines to the expression of PPAR $\alpha$ and PPAR $\gamma$. IC leptin did not significantly affect levels of mucosal PPAR $\alpha$ and PPAR $\gamma$ mRNA (Fig. 7). 

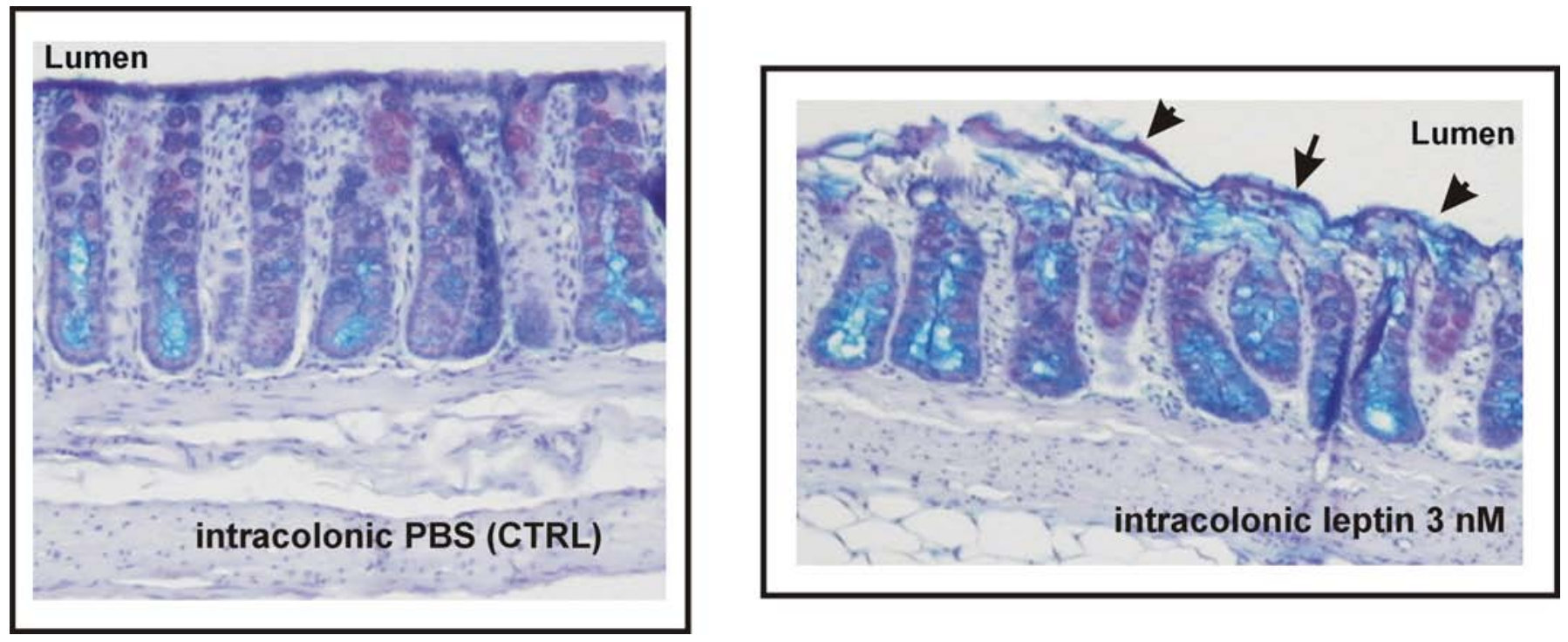

Fig. (3). Acute Intracolonic leptin does not damage the rat colon mucosa. We carried out a histological analysis of rat distal colons, 3 hours after the injection of PBS (control). $3 \mathrm{nM}$ recombinant mouse leptin was directly delivered into the colonic lumen. Sections $(4 \mu \mathrm{m})$ of colonic mucosa, stained with alcian blue/ periodic acid-Schiff reaction, revealed goblet cells. Note that in colon mucosa from intracolonic leptin ( $3 \mathrm{nM}$ )-treated rats (right panel) the crypt lumen was expanded and the release of mucus was seen from goblet cells; some mucus was also seen at the surface of the epithelium (arrows).

PPAR $\alpha$ mRNA levels in control DSS-treated rats were significantly lower than those in control rats $(-45 \% ; P<0.05$ vs control), whereas PPAR $\gamma$ mRNA levels did not change. Treatment of DSS-treated rats with IC leptin restored mucosal PPAR $\alpha$ mRNA levels and enhanced the levels of PPAR $\gamma$ mRNA two-fold.

\section{DISCUSSION}

In this study, we demonstrated for the first time that leptin acting from the lumen of the colon rapidly stimulates phosphorylation of STAT-3 and p44 mitogen-activated protein kinase MAPK, two intracellular events essential for leptin action. These data are consistent with those showing that leptin activates STAT-3 in the stomach [29], and activates MAPK in the duodenum [23, 30] and in other biological systems if acting in an endocrine manner [31]. Intracolonic leptin activation of these signalling pathways was followed by increased SOCS-3 protein production, which has been reported to function as a negative regulator of leptinreceptor signalling by interfering with STAT-3 [32, 33]. Our data also demonstrate this regulatory effect. Interestingly, the concentrations of leptin inducing activation of STAT3 and MAPK in this study were compatible with those necessary for the activation of leptin receptors and with the concentrations of leptin detected in the colon luminal content [present study \& 21,22]. These results along with the expression of leptin receptors on the apical side of the colonocytes [34, 35] support the idea that these receptors are primary targets for leptin in colon juice $[21,22,36]$. This seems likely as the activation of STAT3 and MAPK was followed by induction of COX-2 and enhanced production of mucosal $\mathrm{PGE}_{2}$. Interestingly, in vitro studies previously reported JAK2dependent activation of COX-2 and $\mathrm{PGE}_{2}$ production in oesophageal [37, 38] and macrophage J774.1 cells [39, 40]. Moreover, in the rat brain, leptin can induce COX-2 expression via an interaction with interleukin-1 beta [41]. Thus, we suggested that apical activation of leptin receptors on colonic epithelial cells may be an important factor in driving mucosal COX-2 expression, probably through STAT3- and MAPK- dependent pathways.

COX-2 is an important rate-limiting enzyme involved in the production of prostaglandins from arachidonic acid. Unlike COX-1, the constitutive "housekeeping" isoform, COX-2, is an inducible isoform of which expression occurs in most cells in response to tissue injury and can be upregulated by growth factors and various cytokines [42]. COX-2 mRNA and protein production are up-regulated at the ulcer margin in relation to enhanced epithelial cell proliferation and increased expression of growth factors. By contrast, we have previously reported that colon leptin activates mucus secretion $[21,22]$, an effect consistent with our current findings. Taking into account the leading role of COX-2 and the mucus layer in the maintenance of mucosal integrity, we suggested that the apical effects of leptin on colon epithelial cells contribute to repairing tissue damage and/or attenuating colonic inflammation. This is supported by data demonstrating that deletion of the gene encoding PGE receptor EP4 subtype is associated with an increased susceptibility of the mice to DSS colitis [43]. These data along with the reported increased levels of leptin in colonic juice in IBD [22] highlight the physiological relevance of these findings in controlling intestinal inflammation.

There is convergent data arguing for a pro-inflammatory function to circulating leptin. This function, however, contrasts with the lower reported circulating leptin levels in IBD patients [44], but appears be consistent with the reported over-expression of leptin and its receptors in mesenteric adipose tissue of IBD patients [45]. Moreover, this overexpression of leptin was demonstrated in gastric mucosa colonised with Helicobacter pylori $[19,20]$ and in the colon of IBD patients with increased leptin levels in their luminal contents [22 and, unpublished results]. It is therefore possible that, in the inflamed tissue, the expression of leptin is 


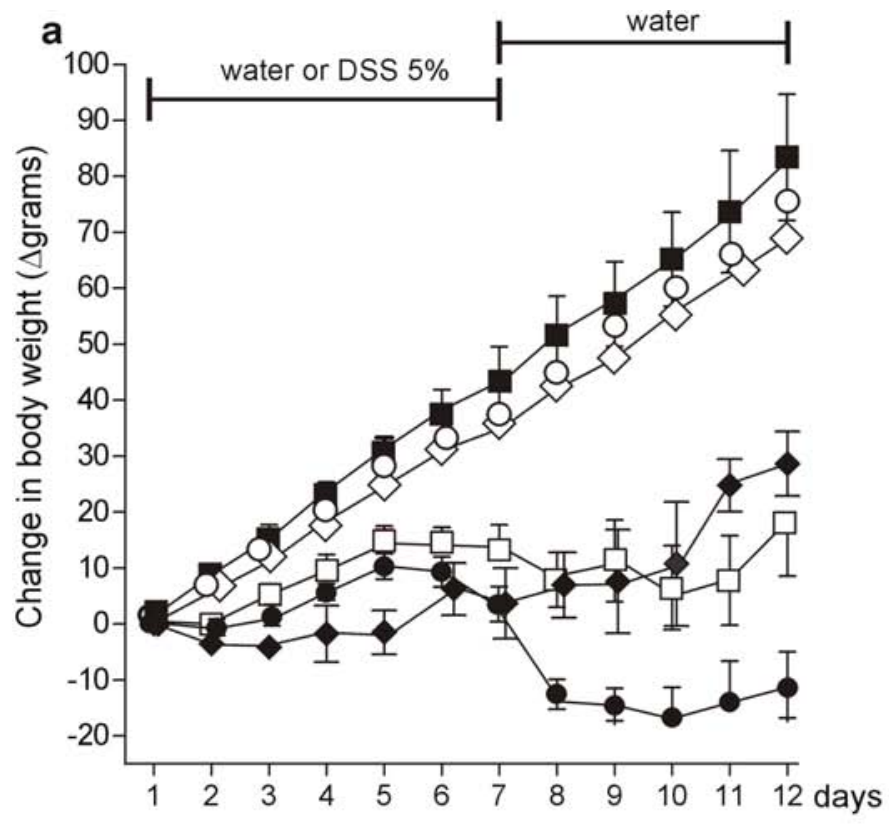

b
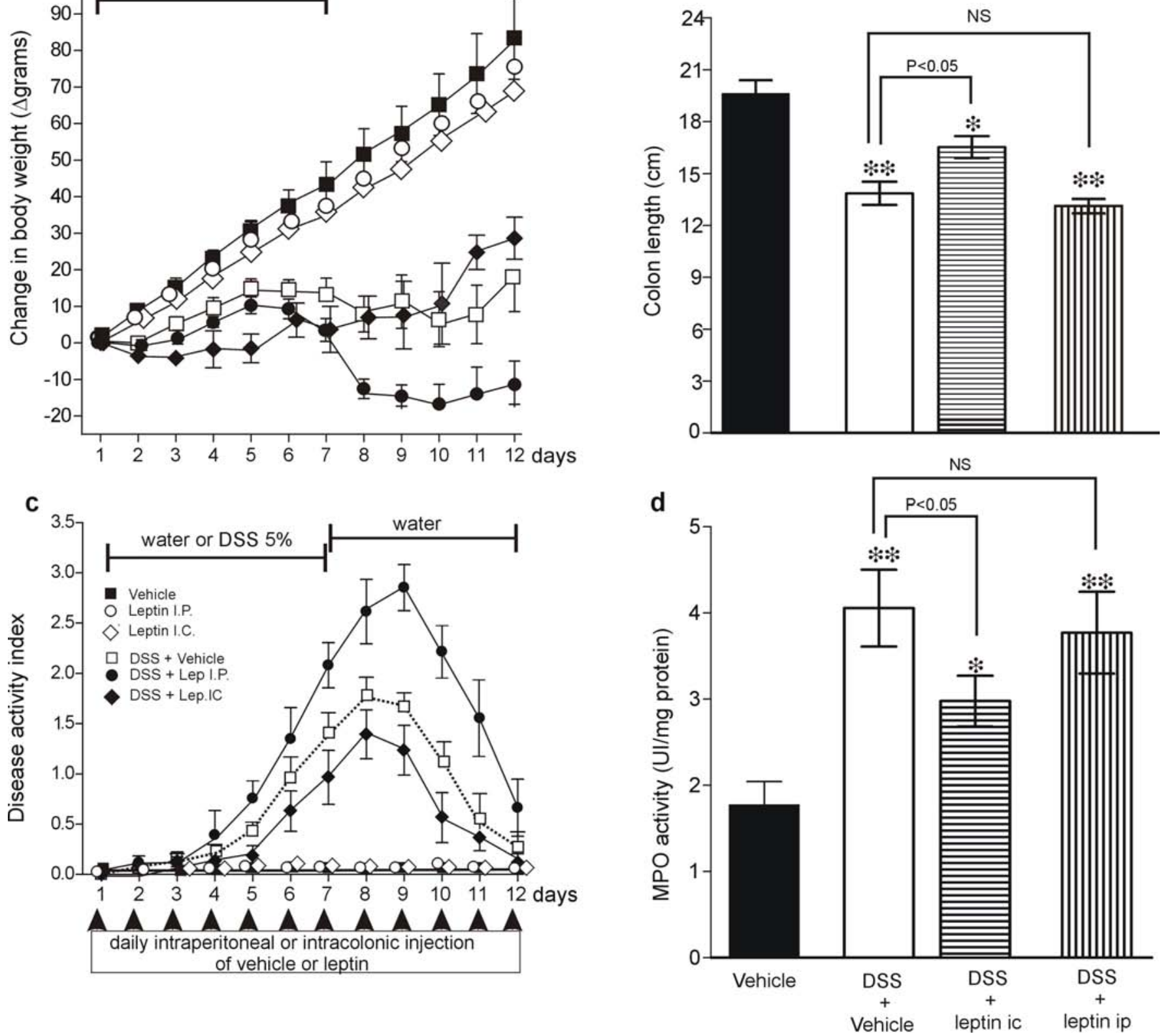

Fig. (4). Effects of IP vs IC chronic leptin during DSS treatment in rats. (a) Changes in daily body weight, (b) the shortening of colon, (c) disease activity index and (d) tissue-associated MPO activity. MPO activity was measured in colon homogenates as described in Materials and Methods. Each point and/or column represents the mean \pm SEM of at least 15 rats. ${ }^{*} P<0.05 ; * * P<0.01$ vs control (vehicle).

dependent on the severity and the timeline of the inflammatory processes. This is the case for skin tissue [46], and gastrointestinal mucosa $[17,19,20,22]$, which has been suggested to represent sources of leptin potentially secreted in the lumen during inflammation. Whether over expression of leptin is the driving force underlying inflammatory responses or simply represent a marker of an inflammatory state is largely unknown. In one interesting study, it has been demonstrated in mice that 48 hours after the intrarectal injection of leptin the colonic epithelial wall was significantly damaged with epithelial exfoliation, indicating a proinflammatory function [22]. However, identifying the exact relationship between leptin acting apically of colon epithelial cells and intestinal inflammatory processes requires further study. Although leptin activates the nuclear transcription factor NF- $\kappa$ B $[22,47]$, implicated in IBD [48], this does not preclude a protective role for leptin. Indeed, data obtained from specific ablation of IKK- $\beta$ in intestinal epithelial cells suggests that the primary function of NF- $\mathrm{KB}$ activation in IEC in response to injury is to protect the inflamed mucosa [49]. Intestinal inflammation alters patterns of proliferation and differentiation, and leptin exerts proliferative effects [37, $47,50,51]$; thus, we can still question the beneficial effects of leptin acting locally in intestinal inflammation.

This data prompted us to analyse the role of gut leptin on DSS-induced colonic inflammation. This model is a wellcharacterised model with predictable disease progression. However, it also has several clinical, biochemical and his- 

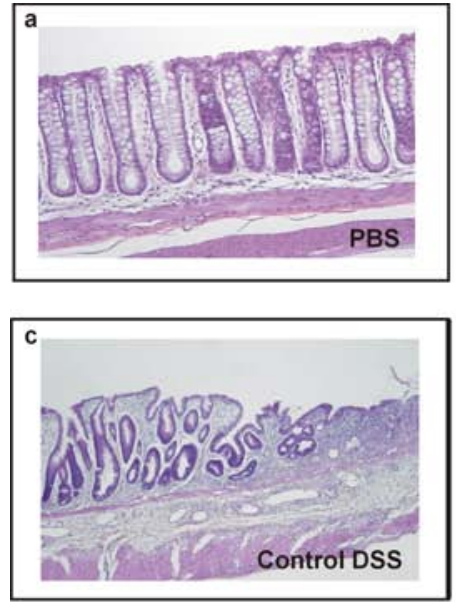
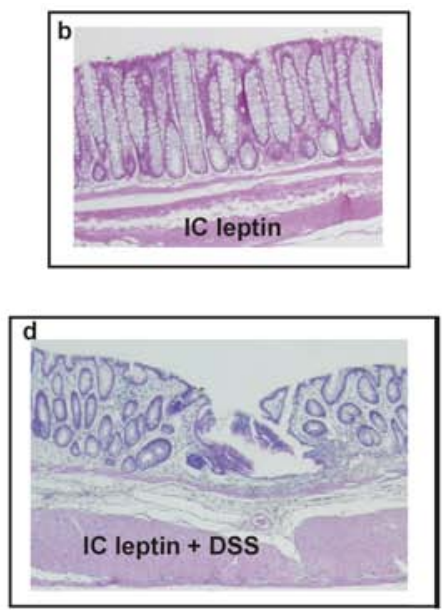

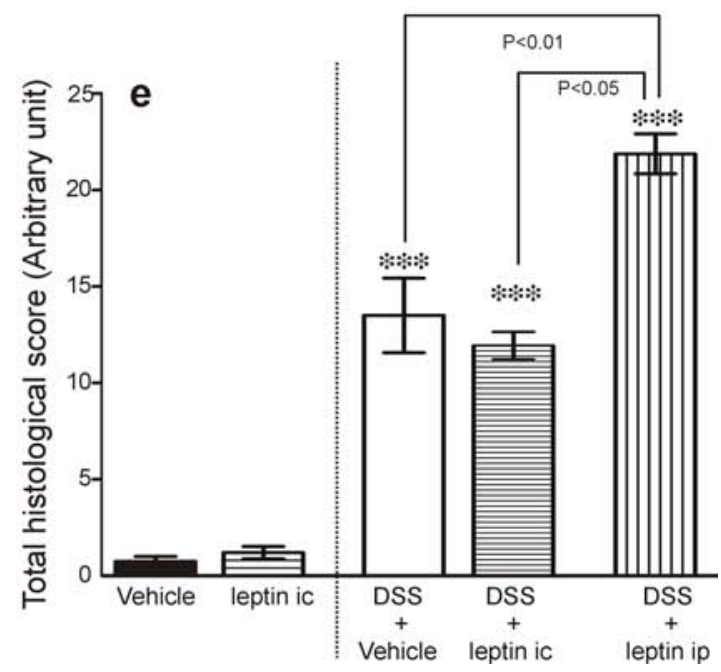

Fig. (5). Histological changes in the colon mucosa of control and DSS rats treated with intraperitoneal or intracolonic leptin. Haematoxylin-eosin staining was performed on colon sections prepared from paraffin embedded samples fixed in Bouin solution and processed as described in Material \& Methods. Shown are representative photomicrographs of H\&E-stained paraffin sections of distal colon from control (a), IC leptin treated (b), DSS alone (c) and IC leptin-DSS treated (d). Histological scores of disease severity (e). Each column represents the mean \pm SEM of at least 15 rats. $* * * P<0.001$ vs control (vehicle).

tological features that closely resemble UC in humans [52, 53]. The major finding of this study was that leptin acting luminally of mucosa attenuates the severity of DSS-induced colitis, whereas treatment with peripheral leptin does not. The analysis of inflammation-related genes revealed an unexpected feature for topically supplemented leptin. With the exception of mucosal TNF $\alpha$ mRNA levels, DSS-induction of pro-inflammatory IL- 8 and IL- $1 \beta$ mediators was prevented by luminal leptin. It is noteworthy that challenge of the colon lumen by leptin is not altered by its own colonic epithelial wall and the expression of TNF $\alpha$ and IL-1 $\beta$. Collectively, these data suggest that leptin acting at apical side of colon epithelial cells is unlikely to function as a pro-inflammatory cytokine. They rather suggest that upon injury of the mucosa, leptin is likely to antagonise pro-inflammatory pathways to reduce the severity of colitis. This is supported by findings demonstrating that topically supplemented leptin improved re-epithelialisation of wounds in leptin deficient $o b / o b$ mice [46].

Peroxisome-proliferator activated receptor- $\alpha$ and $\gamma$ (PPAR- $\alpha, \gamma)$ are nuclear receptors reported as regulators of several genes involved in metabolic control [54]. Several studies have reported that the activation of PPAR $\gamma$ by specific ligands attenuates the severity and/or delays the onset of colitis in experimental mouse models of IBD [55-58]. Moreover, mice with specific deletion of PPAR- $\gamma$ throughout the intestinal epithelium exhibited a great susceptibility to DSS-induced colitis arguing for a direct role of PPAR $\gamma$ in the colon mucosa [59]. We analysed the mechanisms further and found that intracolonic leptin completely restores the reduced levels of mucosa PPAR $\alpha$ in DSS-induced colitis in rats, and potently enhances levels of mucosa PPAR $\gamma$. Therefore, this increase in PPAR- $\gamma$ mRNA probably contributes to reducing the severity of DSS colitis in rats, yet this remains to be clearly demonstrated.

In summary, our findings support the idea that leptin operating through its apical receptors coupled with the
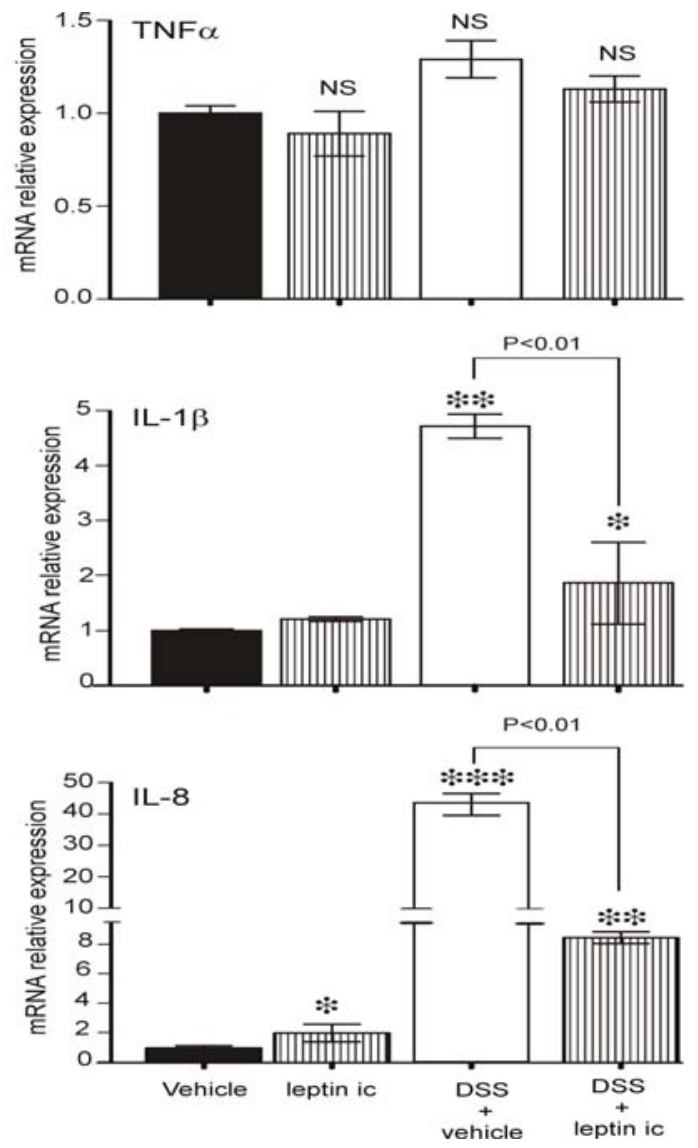

Fig. (6). Chronic intracolonic leptin on inflammation-related genes in DSS colitis rats. Total RNA was extracted from a segment from the proximal and middle colon in control (drinking water) and DSS rats receiving intracolonic PBS or $6 \mathrm{nM}$ leptin; these samples were analysed by quantitative RT-PCR, as described in the Materials and Methods section. Quantification of mRNA encoding TNF- $\alpha$ (upper panel), IL-1 $\beta$ (middle panel), and IL-8 (lower panel) normalised to mRNA for HPRT. NS: non significant; * $P<0.05$; ** $P<0.01$; *** $P<0.001$ vs Control. 


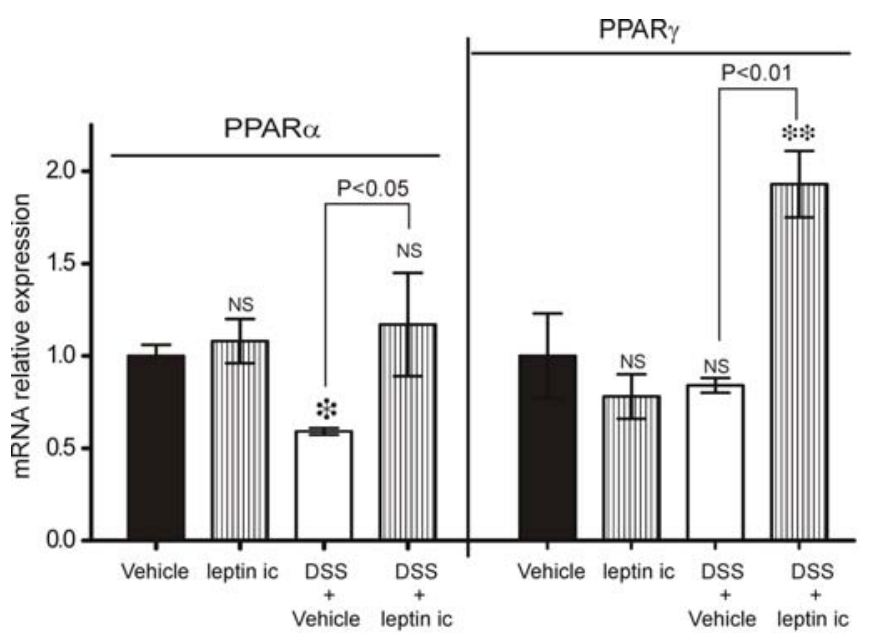

Fig. (7). Intracolonic leptin prevents reduction of PPAR $\alpha$ and induces PPAR $\gamma$ in colon mucosa in DSS rats. Total RNA was extracted from the middle colon in control and DSS rats receiving intracolonic vehicle or leptin, and was analysed by quantitative RTPCR, as described in the Material and Methods section. Quantification of mRNA encoding PPAR $\alpha$ and PPAR $\gamma$ normalised to mRNA for HPRT. One-way ANOVA with Tukey-Kramer multiple comparison post-test. NS: non significant; $* P<0.05$; $* * P<0.01$ vs control.

activation of STAT-3- and MAPKinase-dependent pathways may have a beneficial effect on the integrity of the epithelium, during injury of the intestinal mucosa.

\section{ACKNOWLEDGEMENTS}

These studies were supported by the French National Institute of Medical Research (Inserm) and by a grant to SG from the Fondation pour la Recherche Médicale.

\section{REFERENCES}

[1] Zhang Y, Proenca R, Maffei M, Barone M, Leopold L, Friedman JM. Positional cloning of the mouse obese gene and its human homologue. Nature 1994; 372: 425-2.

[2] Bado A, Levasseur S, Attoub S, et al. The stomach is a source of leptin. Nature 1998; 394: 790-93.

[3] Groschl M, Rauh M, Wagner R, et al. Identification of leptin in human saliva. J Clin Endocrinol Metab 2001; 86: 5234-39.

[4] Masuzaki H, Ogawa Y, Sagawa N, et al. Nonadipose tissue production of leptin: leptin as a novel placenta-derived hormone in humans. Nat Med 1997; 3: 1029-33.

[5] Sobhani I, Bado A, Vissuzaine C, et al. Leptin secretion and leptin receptor in the human stomach. Gut 2000; 47: 178-83.

[6] Lee GH, Proenca R, Montez JM, et al. Abnormal splicing of the leptin receptor in diabetic mice. Nature 1996; 379: 632-5.

[7] Tartaglia LA, Dembski M, Weng X, et al. Identification and expression cloning of a leptin receptor, OB-R. Cell 1995; 83: 126371.

[8] Bernotiene E, Palmer G, Gabay C. The role of leptin in innate and adaptive immune responses. Arthritis Res Ther 2006; 8: 217-26.

[9] Fantuzzi G, Faggioni R. Leptin in the regulation of immunity, inflammation, and hematopoiesis. J Leukoc Biol 2000; 68: 437-46.

[10] Siegmund B, Lehr HA, Fantuzzi G. Leptin: a pivotal mediator of intestinal inflammation in mice. Gastroenterology 2002; 122: 201125.

[11] Fantuzzi G, Sennello JA, Batra A, et al. Defining the role of T cellderived leptin in the modulation of hepatic or intestinal inflammation in mice. Clin Exp Immunol 2005; 142: 31-38.

[12] Siegmund B, Sennello JA, Jones-Carson J, et al. Leptin receptor expression on $\mathrm{T}$ lymphocytes modulates chronic intestinal inflammation in mice. Gut 2004; 53: 965-72.
[13] Faggioni R, Fantuzzi G, Gabay C, et al. Leptin deficiency enhances sensitivity to endotoxin-induced lethality. Am J Physiol 1999; 276: R136-42.

[14] Takahashi N, Waelput W, Guisez Y. Leptin is an endogenous protective protein against the toxicity exerted by tumor necrosis factor. J Exp Med 1999; 189: 207-12.

[15] Jaworek J, Bonior J, Pierzchalski P, et al. Leptin protects the pancreas from damage induced by caerulein overstimulation by modulating cytokine production. Pancreatology 2002; 2: 89-99.

[16] Erkasap N, Uzuner K, Serteser M, Koken T, Aydin Y. Gastroprotective effect of leptin on gastric mucosal injury induced by ischemia-reperfusion is related to gastric histamine content in rats. Peptides 2003: 24: 1181-87.

[17] Konturek PC, Konturek SJ, Brzozowski T, Hahn EG. Gastroprotection and control of food intake by leptin. Comparison with cholecystokinin and prostaglandins. J Physiol Pharmacol 1999; 50: 3948.

[18] Cakir B, Bozkurt A, Ercan F, Yegen BC. The anti-inflammatory effect of leptin on experimental colitis: involvement of endogenous glucocorticoids. Peptides 2004; 25: 95-104.

[19] Konturek JW, Konturek SJ, Kwiecien N, et al. Leptin in the control of gastric secretion and gut hormones in humans infected with Helicobacter pylori. Scand J Gastroenterol 2001; 36: 1148-54.

[20] Nishi Y, Isomoto H, Uotani S, et al. Enhanced production of leptin in gastric fundic mucosa with Helicobacter pylori infection. World J Gastroenterol 2005; 11: 695-99.

[21] Plaisancie P, Ducroc R, El Homsi M, et al. Luminal leptin activates mucin-secreting goblet cells in the large bowel. Am J Physiol Gastrointest Liver Physiol 2006; 290: G805-812.

[22] Sitaraman S, Liu X, Charrier L, et al. Colonic leptin: source of a novel proinflammatory cytokine involved in IBD. FASEB J 2004; 18: 696-8.

[23] Guilmeau S, Buyse M, Tsocas A, Laigneau JP, Bado A. Duodenal leptin stimulates cholecystokinin secretion: evidence of a positive leptin-cholecystokinin feedback loop. Diabetes 2003; 52: 1664-72.

[24] Gaudio E, Taddei G, Vetuschi A, et al. Dextran sulfate sodium (DSS) colitis in rats: clinical, structural, and ultrastructural aspects. Dig Dis Sci 1999; 44: 1458-75.

[25] Siegmund B, Fantuzzi G, Rieder F, et al. Neutralization of interleukin-18 reduces severity in murine colitis and intestinal IFNgamma and TNF-alpha production. Am J Physiol Regul Integr Comp Physiol 2001; 281: R1264-73.

[26] Barbier M, Attoub S, Joubert M, et al. Proinflammatory role of leptin in experimental colitis in rats benefit of cholecystokinin-B antagonist and beta3-agonist. Life Sci 2001; 69: 567-80.

[27] Radeva G, Buyse M, Hindlet P, et al. Regulation of the oligopeptide transporter, PEPT-1, in DSS-induced rat colitis. Dig Dis Sci 2007; 52: 1653-61.

[28] Linard C, Gremy O, Benderitter M. Reduction of PPAR \{gamma\} expression by $\{$ gamma $\}$-irradiation as a mechanism contributing to inflammatory response in rat colon: Modulation by the 5-ASA agonist. J Pharmacol Exp Ther 2008; 324(3): 911-20.

[29] Goiot H, Attoub S, Kermorgant S, et al. Antral mucosa expresses functional leptin receptors coupled to STAT-3 signaling, which is involved in the control of gastric secretions in the rat. Gastroenterology $2001 ; 121: 1417-27$.

[30] Hardwick JC, Van Den Brink GR, Offerhaus GJ, Van Deventer SJ, Peppelenbosch MP. Leptin is a growth factor for colonic epithelial cells. Gastroenterology 2001; 121: 79-90.

[31] Tartaglia LA. The leptin receptor. J Biol Chem 1997; 272: 609396.

[32] Peiser C, McGregor GP, Lang RE. Leptin receptor expression and suppressor of cytokine signaling transcript levels in high-fat-fed rats. Life Sci 2000; 67: 2971-81.

[33] Waelput W, Verhee A, Broekaert D, et al. Identification and expression analysis of leptin-regulated immediate early response and late target genes. Biochem J 2000; 348: 55-61.

[34] Aparicio T, Guilmeau S, Goiot H, et al. Leptin reduces the development of the initial precancerous lesions induced by azoxymethane in the rat colonic mucosa. Gastroenterology 2004; 126: 499-510.

[35] Buyse M, Berlioz F, Guilmeau S, et al. PepT1-mediated epithelial transport of dipeptides and cephalexin is enhanced by luminal leptin in the small intestine. J Clin Invest 2001; 108: 1483-94.

[36] El Homsi M, Ducroc R, Claustre J, et al. Leptin modulates the expression of secreted and membrane-associated mucins in colonic 
epithelial cells by targeting PKC, PI3K, and MAPK pathways. Am J Physiol Gastrointest Liver Physiol 2007; 293: G365-73.

[37] Beales IL, Ogunwobi OO. Leptin synergistically enhances the antiapoptotic and growth-promoting effects of acid in OE33 oesophageal adenocarcinoma cells in culture. Mol Cell Endocrinol 2007; 274: 60-68.

[38] Ogunwobi O, Mutungi G, Beales IL. Leptin stimulates proliferation and inhibits apoptosis in Barrett's esophageal adenocarcinoma cells by cyclooxygenase-2-dependent, prostaglandin-E2-mediated transactivation of the epidermal growth factor receptor and c-Jun NH2terminal kinase activation. Endocrinology 2006; 147: 4505-16.

[39] Lee FY, Li Y, Yang EK, et al. Phenotypic abnormalities in macrophages from leptin-deficient, obese mice. Am J Physiol 1999; 276: C86-394.

[40] Raso GM, Pacilio M, Esposito E, Coppola A, Di Carlo R, Meli R. Leptin potentiates IFN-gamma-induced expression of nitric oxide synthase and cyclo-oxygenase-2 in murine macrophage J774A.1. Br J Pharmacol 2002; 137: 799-04.

[41] Inoue W, Poole S, Bristow AF, Luheshi GN. Leptin induces cyclooxygenase-2 via an interaction with interleukin-1beta in the rat brain. Eur J Neurosci 2006; 24: 2233-45.

[42] Halter F, Tarnawski AS, Schmassmann A, Peskar BM. Cyclooxygenase 2-implications on maintenance of gastric mucosal integrity and ulcer healing: controversial issues and perspectives. Gut 2001; 49: 443-53.

[43] Kabashima K, Saji T, Murata T, et al. The prostaglandin receptor EP4 suppresses colitis, mucosal damage and CD4 cell activation in the gut. J Clin Invest 2002; 109: 883-93.

[44] Karmiris K, Koutroubakis IE, Xidakis C, Polychronaki M, Kouroumalis EA. The effect of infliximab on circulating levels of leptin, adiponectin and resistin in patients with inflammatory bowel disease. Eur J Gastroenterol Hepatol 2007; 19: 789-94.

[45] Barbier M, Vidal H, Desreumaux P, et al. Overexpression of leptin mRNA in mesenteric adipose tissue in inflammatory bowel diseases. Gastroenterol Clin Biol 2003; 27: 987-91.

[46] Frank S, Stallmeyer B, Kampfer H, Kolb N, Pfeilschifter J. Leptin enhances wound re-epithelialization and constitutes a direct function of leptin in skin repair. J Clin Invest 2000; 106: 501-09.

[47] Rouet-Benzineb P, Aparicio T, Guilmeau S, et al. Leptin counteracts sodium butyrate-induced apoptosis in human colon cancer HT29 cells via NF-kappaB signaling. J Biol Chem 2004; 279: 16495502 .
[48] Schottelius AJ, Baldwin AS, Jr. A role for transcription factor NFkappa B in intestinal inflammation. Int J Colorectal Dis 1999; 14: $18-28$.

[49] Chen LW, Egan L, Li ZW, Greten FR, Kagnoff MF, Karin M. The two faces of IKK and NF-kappaB inhibition: prevention of systemic inflammation but increased local injury following intestinal ischemia-reperfusion. Nat Med 2003; 9: 575-81

[50] Fombonne J, Charrier C, Goddard I, Moyse E, Krantic S. Leptinmediated decrease of cyclin A2 and increase of cyclin D1 expression: relevance for the control of prepubertal rat Leydig cell division and differentiation. Endocrinology 2007; 148: 2126-37.

[51] Ogunwobi OO, Beales IL. Cyclo-oxygenase-independent inhibition of apoptosis and stimulation of proliferation by leptin in human colon cancer cells. Dig Dis Sci 2007; 52: 1934-45.

[52] Mahler M, Bristol IJ, Leiter EH, et al. Differential susceptibility of inbred mouse strains to dextran sulfate sodium-induced colitis. Am J Physiol 1998; 274: G544-51.

[53] Tamaru T, Kobayashi H, Kishimoto S, Kajiyama G, Shimamoto F, Brown WR. Histochemical study of colonic cancer in experimental colitis of rats. Dig Dis Sci 1993; 38: 529-37.

[54] Schoonjans K, Martin G, Staels B, Auwerx J. Peroxisome proliferator-activated receptors, orphans with ligands and functions. Curr Opin Lipidol 1997; 8: 159-66.

[55] Desreumaux P, Dubuquoy L, Nutten S, et al. Attenuation of colon inflammation through activators of the retinoid $\mathrm{X}$ receptor $(\mathrm{RXR}) /$ peroxisome proliferator-activated receptor gamma (PPARgamma) heterodimer. A basis for new therapeutic strategies. J Exp Med 2001; 193: 827-38.

[56] Dubuquoy L, Rousseaux C, Thuru X, et al. PPARgamma as a new therapeutic target in inflammatory bowel diseases. Gut 2006; 55: $1341-49$.

[57] Katayama K, Wada K, Nakajima A, et al. A novel PPAR gamma gene therapy to control inflammation associated with inflammatory bowel disease in a murine model. Gastroenterology 2003; 124: 1315-24.

[58] Su CG, Wen X, Bailey ST, et al. A novel therapy for colitis utilizing PPAR-gamma ligands to inhibit the epithelial inflammatory response. J Clin Invest 1999; 104: 383-89.

[59] Adachi M, Kurotani R, Morimura K, et al. Peroxisome proliferator activated receptor gamma in colonic epithelial cells protects against experimental inflammatory bowel disease. Gut 2006; 55: 1104-13.

(C) Nazaret et al.; Licensee Bentham Open.

This is an open access article licensed under the terms of the Creative Commons Attribution Non-Commercial License (http://creativecommons.org/licenses/bync/3.0/) which permits unrestricted, non-commercial use, distribution and reproduction in any medium, provided the work is properly cited. 